\title{
IMPACTO DO INOVAR-AUTO NAS EMISSÕES VEICULARES
}

\author{
Natália G. de Moraes ${ }^{1}$, Bernardo V. Z. Machado ${ }^{1}$ \\ ${ }^{1}$ Universidade Federal do Rio de Janeiro - Programa de Planejamento Energético \\ E-mails: natalia.moraes@gmail.com, bezurli@gmail.com
}

\section{RESUMO}

Políticas de eficiência energética são poderosos instrumentos para a redução da emissão de poluentes. Neste contexto, o Programa Inovar-Auto tem como um de seus pilares o aumento da eficiência energética, através de incentivo tributário. Para se habilitar ao programa, a empresa deve comprometer-se a cumprir a exigência de consumo energético máximo, em $\mathrm{MJ} / \mathrm{km}$, calculado em função da massa dos veículos vendidos no Brasil. Desta forma, a meta de eficiência por montadora é diferenciada, pois depende da preferência do consumidor e das características de modelos comercializados.

Esse trabalho tem dois objetivos principais: $i$ ) mensurar o ganho de eficiência a ser auferido por montadora para que sejam alcançadas as metas do Inovar-Auto, e ii) calcular o impacto desta redução de consumo energético sobre as emissões de Gases do Efeito Estufa (GEE). A metodologia utilizada tem como base o rendimento médio dos veículos vendidos por modelo e por empresa de acordo com o Programa de Etiquetagem Veicular do INMETRO, dados de licenciamentos de veículos da FENABRAVE, e parâmetros de emissão veicular da CETESB. Além dos resultados estatísticos, o trabalho inclui análise de possíveis impactos do InovarAuto sobre o perfil de vendas de veículos leves no Brasil e suas repercussões nas emissões de GEE.

\section{INTRODUÇÃO}

Nos últimos dez anos o consumo de energia no Brasil aumentou cerca de 43\%, totalizando 260 milhões de tep (tonelada equivalente de petróleo) em 2013, contra 182 milhões de tep em 2003. Neste mesmo período, o consumo de gasolina e álcool etílico (combustíveis destinados quase em sua totalidade para o abastecimento da frota de veículos leves) aumentou cerca de 90\%, segundo o Balanço Energético Nacional (BEN) [1]. Este crescimento é compatível com o tamanho do mercado doméstico de veículos. Em 2013, com a marca de 3,8 milhões de autoveículos licenciados, o Brasil posicionou-se entre os quatro maiores mercados do mundo, atrás apenas de gigantes como China (21,9 milhões de unidades), EUA (15,9 milhões de unidades), e Japão (5,4 milhões de unidades) [2]. Apesar dos licenciamentos de autoveículos terem apresentado retração em 2014 (3,5 milhões de unidades), o Brasil figura-se como um mercado promissor no longo prazo, principalmente por apresentar uma relação de habitantes por autoveículos baixa (5,3 habitantes por autoveículo) comparado a países em desenvolvimento como México e Argentina (ambos com 3,6 habitantes por autoveículo) e desenvolvidos como Itália (1,7 habitantes por autoveículo) e Alemanha (1,8 habitantes por autoveículo) [2]. Por ser um país em desenvolvimento com expectativa de crescimento de 
renda per capita e de inserção das classes mais baixas no mercado de consumo de bens duráveis, há um grande potencial de aumento da frota de veículos leves na próxima década. De acordo com o Plano Decenal de Energia publicado pela Empresa de Pesquisa Energética (EPE), os licenciamentos de veículos leves devem alcançar 5,1 milhões de unidades em 2023 [3].

Esta conjuntura implica na importância da atuação do governo no sentido de atenuar as externalidades negativas provenientes do crescimento da frota, tais como: ocupação do solo, deterioração da mobilidade urbana, poluição sonora e emissão de poluentes locais e globais. No que diz respeito às emissões, observa-se que o setor de transportes, incluindo o transporte de pessoas e carga, tem uma contribuição relevante. Ao se considerar as emissões antrópicas associadas à matriz energética brasileira, que em 2013, somaram 459 milhões de toneladas de dióxido de carbono equivalente $\left(\mathrm{MtCO}_{2-e q}\right)$, o setor de transportes representou 47\%, $(215,3$ $\mathrm{MtCO}_{2 \text {-eq }}$ ), seguido do setor industrial com 19,4\% (89,2 MtCO2-eq) e do setor residencial com 3,9\% (18,0 $\left.\mathrm{MtCO}_{2 \text {-eq }}\right)$. Outros setores, que inclui o setor agropecuário, serviços, energético, elétrico e as emissões fugitivas, foram responsáveis por $29 \%$, totalizando 136,5 $\mathrm{MtCO}_{2 \text {-eq }}$ [3]. De fato, o transporte de cargas e passageiros preponderantemente rodoviário no Brasil é decisivo para o crescimento das emissões de GEE associados principalmente à queima de gasolina e diesel.

Apesar de o Brasil não estar obrigado a atender metas quantitativas de redução de emissões de GEE no âmbito do Protocolo de Quioto, por ser considerado um país em desenvolvimento econômico, há um esforço do governo em contribuir para a mitigação de suas emissões em linha com o objetivo global e princípio basilar da Convenção Quadro das Nações Unidas de estabilizar a concentração de GEE na atmosfera [3]. Com este intuito, em dezembro de 2009, na $15^{\text {a }}$ Conferência das Partes (COP-15) da UNFCCC, realizada em Copenhague, o Brasil anunciou a meta voluntária de reduzir, em 2020 , entre 36,1 e $38,9 \%$, suas emissões totais de GEE projetadas para aquele ano. Essa meta foi formalizada pela Lei $\mathrm{n}^{\circ} 12.187 / 09$ promulgada naquele mesmo dezembro que, entre outras providências, instituiu a Política Nacional sobre Mudança do Clima (PNMC) e pelo Decreto no 7.390/10 [3].

As políticas de eficiência energética apresentam papel fundamental ao promover a otimização do consumo dos recursos energéticos, mantidos os pressupostos básicos de manutenção das condições de conforto, de segurança e de produtividade dos usuários. No setor de transportes, a aplicação de políticas de eficiência energética podem conduzir a significativas reduções na demanda por combustíveis fósseis e renováveis trazendo implicações tais como; impactos econômicos, vantagens competitivas, redução do impacto ambiental relacionado à cadeia de produção e transporte de combustível e mitigação de emissões de GEE.

Neste contexto, o Programa de Incentivo à Inovação Tecnológica e Adensamento da Cadeia Produtiva de Veículos Automotores - Inovar-Auto, foi instituído pela Lei no 12.715, de 17 de setembro de 2012, e regulamentado pelo Decreto $n^{\circ} 7.819$, de 3 de outubro de 2012, tendo como seu principal compromisso o alcance de níveis mínimos de eficiência energética de todos os veículos comercializados no país, visando o desenvolvimento do setor automotivo brasileiro. Pode-se dizer que o Inovar-Auto tem um caráter inovador no que tange à politica de eficiência energética no segmento de veículos leves no Brasil e sua implementação é um desafio em termos regulatórios e de gestão. Além disso, os resultados alcançados ao longo do período de vigência, até 2017, podem representar passos importantes em relação ao 
desenvolvimento tecnológico da indústria nacional, qualidade dos automóveis, inovação, segurança e consumo de combustíveis e emissões de GEE, dentre outros.

Esse trabalho analisa a implementação do Inovar Auto com dois objetivos principais: $i$ ) mensurar o ganho de eficiência a ser auferido por montadora para que sejam alcançadas as metas do Inovar-Auto, e ii) calcular o impacto desta redução de consumo energético sobre as emissões de Gases do Efeito Estufa (GEE). Com este intuito, na primeira sessão é feita uma breve descrição de políticas de eficiência energética para veículos leves no mundo. $\mathrm{Na}$ segunda sessão, relata-se o histórico das principais políticas de eficiência energética no setor de transportes no Brasil. Na terceira sessão, é feita uma descrição do processo de habilitação das montadoras ao programa Inovar Auto, bem como das metas para o alcance de benefícios tributários adicionais. A quarta sessão é destinada à descrição da metodologia utilizada no trabalho e dos cálculos e resultados de metas de eficiência energética por montadora, bem como do cálculo das emissões de GEE. Por fim, os resultados encontrados são analisados na conclusão.

\section{POLÍTICAS DE EFICIENCIA ENERGÉTICA PARA VEÍCULOS LEVES NO MUNDO}

Analisar as melhores práticas internacionais é fundamental para compreender e avaliar a política de eficiência veicular brasileira. Dessa forma, as experiências internacionais que serão avaliadas nesse trabalho são a norte-americana e a europeia.

\subsection{Estados Unidos}

Em resposta ao aumento de preços de petróleo no início da década de 1970, o Corporate Average Fuel Economy (CAFE - economia de combustível corporativa média, em tradução livre) foi aprovado pelo congresso americano em 1975. A lei originalmente buscava dobrar a eficiência de veículos de passageiros, de $13,5 \mathrm{mpg}$ (milhas por galão) para 27,5 mpg, dentro de 10 anos. No mesmo período, a eficiência de caminhões leves aumentou de 11,6 mpg para 19,5 mpg. Durante a década de 80, com a queda dos preços de petróleo e algum lobby por parte de montadoras, o programa não efetuou nenhum incremento em sua meta por quase duas décadas [4].

Somente na década de 2000, mais especificamente no ano de 2007, o congresso americano voltou a aumentar os requerimentos de eficiência do CAFE e, a partir de 2009, o governo passou a adotar padrões de eficiência progressivamente exigentes [4]. Atualmente, as metas americanas são determinadas em termos de emissões de $\mathrm{CO}_{2}$ por distância percorrida e o objetivo proposto pelo programa é alcançar a emissão de 163 gramas de $\mathrm{CO}_{2}$ equivalente por milha em 2025, para veículos leves. Caso esse padrão de emissão seja alcançado somente por meio de maior eficiência dos veículos, isso significaria um consumo de 54,5 mpg [5].

Os padrões de emissão da EPA são determinados por curvas em função do peso do veículo, de modo que, cada veículo possua uma meta específica, dependendo do seu peso. Em geral, veículos mais pesados possuem metas maiores (podem emitir mais $\mathrm{CO}_{2}$ por distância percorrida). De forma semelhante à proposta brasileira do Inovar-Auto, cada montadora deve possuir uma meta para a sua frota e nenhum veículo é obrigado a cumprir individualmente os padrões de eficiência. $\mathrm{O}$ objetivo dessa forma de regulação é distribuir o ônus da meta por 
todos os veículos e todas as montadoras, de forma a não incentivar a construção de veículos de um determinado tipo ou tamanho [5].

\subsection{União Europeia}

Inicialmente, a União Europeia buscou incentivar a eficiência da indústria automotiva por meio de acordos voluntários com as montadoras e o objetivo era de atingir uma eficiência média para a indústria de 140 gramas de $\mathrm{CO}_{2}$ por quilômetro até o ano de 2008 (UNEP, 2013). Contudo, a meta não foi atingida e, em abril de 2009, a comissão europeia estabeleceu regulações mandatórias com o objetivo de atingir a emissão média de $130 \mathrm{~g} \mathrm{CO}_{2} / \mathrm{km}$ para a frota no ano de 2015 [6].

A regulação europeia, assim como a brasileira, é baseada na massa do veículo. O valor máximo médio permitido de emissões para cada montadora, para o ano de 2015, é calculado pela seguinte equação [6]:

Equação 1: Meta de emissões da União Europeia

Emissões permitidas $\left(\mathrm{g} \mathrm{CO}_{2} / \mathrm{km}\right)=130+\mathrm{a} \cdot\left(\mathrm{M}-\mathrm{M}_{0}\right)$

Onde "a" é Coeficiente angular da reta, igual a 0,0457 ; " $\mathrm{M}$ " é a média ponderada da massa dos carros pelas vendas, para cada montadora; e " $\mathrm{M}_{0}$ " é igual a 1289 (massa média da frota à época da elaboração da regulação). Por meio dessa equação, constrói-se uma curva de valores limite (chamada "limit value curve") que especifica a eficiência média mínima a ser atingida pelas montadoras.

Apenas a média da frota é regulada, o que permite que as montadoras continuem fabricando veículos com emissões acima das metas se elas forem compensadas por veículos abaixo da meta. Para cumprir a regulação, a montadora deve garantir que a média ponderada pelas vendas de todos os seus novos carros não exceda a limit value curve [6]. Posteriormente, a União Europeia estabeleceu novas metas - atingir a emissão de $95 \mathrm{~g} \mathrm{CO}_{2} / \mathrm{km}$ no ano de 2020 $[6]$.

\section{POLITICAS DE EFICIENCIA ENERGÉTICA PARA VEÍCULOS NO BRASIL}

Dentre as políticas de eficiência energética destinada aos veículos leves no Brasil, destaca-se o Programa Brasileiro de Etiquetagem Veicular (PBEV), aprovado em novembro de 2008, através da portaria INMETRO $\mathrm{n}^{\circ} 391$, em linha com o objetivo de promover a conservação e uso racional de energia estabelecido pela Lei n. ${ }^{\circ} 10.295$, de 17 de outubro de 2001. O PBE é coordenado pelo Instituto Nacional de Metrologia, Normalização e Qualidade Industrial (INMETRO) e tem como um de seus objetivos contribuir para equilibrar a relação de consumo diminuindo a assimetria de informação existente entre quem compra e quem vende [7].

No caso do PBE veicular, verifica-se que, por um lado, consumidores mais bem informados podem fazer escolhas mais adequadas às suas expectativas de rendimento energético $(\mathrm{km} / \mathrm{l})$, dada uma categorias de veículos. Por outro lado, as montadoras podem diferenciar seus produtos com base na eficiência e economia de combustível. De uma forma geral, a sociedade ganha com a coleta e a divulgação de um dado primário de suma importância para o planejamento do setor automotivo. 
A etiqueta afixada de forma voluntária nos modelos participantes é denominada Etiqueta de Conservação de Energia (ENCE) e classifica os modelos veiculares quanto à eficiência energética na sua categoria e traz informações sobre a autonomia do veículo em $\mathrm{km}$ por litro de combustível na cidade e na estrada e sobre a emissão de gás efeito estufa (CO2) e gases poluentes. A classificação vai de 'A' (mais eficiente) até 'E' (menos eficiente). São considerados mais eficientes os automóveis que, nas mesmas condições, gastam menos energia em relação a seus pares e, portanto, consomem menos combustível. Para comparar veículos que usam combustíveis diferentes, os valores de consumo verificados em álcool e gasolina são convertidos em joule, unidade que mede a energia produzida.

De acordo com o INMETRO, os valores de referência da quilometragem por litro são obtidos a partir de medições de consumo efetuadas em laboratório, de acordo com os padrões NBR 7024. As medições laboratoriais normatizadas permitem que todos os modelos sejam testados de forma padronizada, em condições controladas e utilizadas em uma comparação uniforme entre modelos de veículos diferentes, dentro de uma mesma categoria [8].

De acordo com a norma ABNT NBR 7024, a quilometragem por litro de cada veículo tem como base um ciclo urbano e um ciclo rodoviário. A eficiência de cada veículo é posteriormente calculada por meio de uma média harmônica ponderada, conforme a Equação 2 [9]:

Equação 2: Eficiência veicular conforme calculada pela NBR 7024

$$
\text { Eficiência } \text { combustivel }=\frac{1}{\left(\frac{0,55}{\text { Eficiência }_{\text {Ciclo Urbano }}}+\frac{0,45}{\text { Eficiência }_{\text {Ciclo Rodoviário }}}\right)}
$$

Onde:

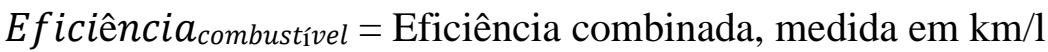

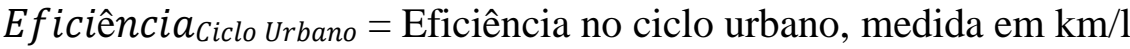

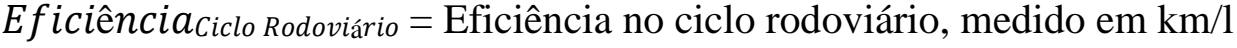

No entanto, observa-se que em condições reais de uso do veículo, o rendimento energético costuma ser diferente daquele resultante das medições de laboratório. Características na forma de dirigir do usuário, condições climáticas, padrões de tráfego, uso de acessórios, tipo de solo e cargas impostas aos veículos são fatores que repercutem em variações do consumo de combustível por quilometro de um mesmo veículo [MDIC]. Sendo assim, com intuito de divulgar valores de rendimento $(\mathrm{km} / \mathrm{l})$ nas etiquetas e tabelas de divulgação do PBE veicular, próximo aqueles percebidos pelos motoristas em seu uso real, o INMETRO utiliza fatores de ajustes desenvolvidos pela Agencia de Proteção Ambiental (EPA) dos Estados Unidos a partir de milhares de dados reais que apontam que $90 \%$ dos usuários conseguem resultados dentro de mais ou menos $20 \%$ dos consumos declarados.

Em 2015, o PBEV chegou à sua $7^{\mathrm{a}}$ edição, com adesão voluntária de 36 fabricantes e com 587 modelos/versões de automóveis e comerciais leves. O aumento da adesão dos fabricantes de automóveis pode ser visto como um indicador do desenvolvimento e aprimoramento do programa que, em seu inicio em 2008 contava com apenas 5 montadoras e 54 modelos inscritos [7].

Outro programa de destaque na promoção da eficiência energética no setor de transportes é o 
Programa Nacional da racionalização do uso dos derivados do petróleo e do gás natural, o CONPET. O CONPET é um programa vinculado ao Ministério de Minas e Energia, executado com apoio técnico e administrativo da Petrobras, criado em 1991 por decreto presidencial, tendo como principais objetivos: racionalizar o consumo dos derivados do petróleo e do gás natural; reduzir a emissão de gases poluentes na atmosfera; promover a pesquisa e o desenvolvimento tecnológico; e fornecer apoio técnico para o aumento da eficiência energética no uso final da energia [10].

O CONPET tem iniciativas em várias áreas, como no uso equipamentos (pneus, aparelhos de gás) e educação. No setor de transportes, o foco é a economia de diesel em veículos pesados (ônibus e caminhões) e redução das emissões. As ações do programa são desenvolvidas por meio de parcerias com sindicatos e federações de transportadores, secretarias estaduais e municipais de transporte e meio ambiente, entrepostos de carregamento ou distribuição de produtos, além de refinarias, terminais de abastecimento, postos de combustível e área de Engenharia da Petrobras.

O Programa também abrange o Selo CONPET de Eficiência Energética, distribuído anualmente pela Petrobras, parceiro do Inmetro no PBEV. O Selo tem o intuito de destacar para o consumidor, aqueles modelos que atingem os graus máximos de eficiência energética na Etiqueta Nacional de Conservação de Energia do Programa Brasileiro de Etiquetagem do INMETRO. No segmento de transporte de veículos leves, são avaliadas 12 categorias (exemplo: subcompactos, compactos, médios, grandes, extragrandes). Na $7^{a}$ edição do PBEV, 152 modelos/versões de 17 marcas foram contemplados com o Selo COMPET [10].

\section{O PROGRAMA INOVAR-AUTO}

O programa de Incentivo à Inovação Tecnológica e Adensamento da Cadeia Produtiva de Veículos Automotores - Inovar-Auto, instituído pela Lei $\mathrm{n}^{\circ} 12.715$, de 17 de setembro de 2012, e regulamentado pelo Decreto $\mathrm{n}^{\circ} 7.819$, de 3 de outubro de 2012, com vigência até dezembro de 2017, é um marco na promoção da eficiência energética dos veículos produzidos no Brasil à medida que este quesito é um de seus principais objetivos. Além disso, o programa visa atrair investimentos em novas unidades fabris e modernizar as unidades já existentes, promover o adensamento da cadeia produtiva e estimular novos investimentos em P\&D, engenharia e ferramentaria. Paralelamente, o programa almeja ampliar a capacitação de fornecedores brasileiros e aumentar as exportações de veículos, com repercussões positivas na redução dos déficits da balança comercial [11].

Até o final de agosto de 2014, 52 empresas (21 fabricantes, 15 importadores e 16 novos investidores) já haviam sido habilitadas. Os novos investimentos confirmados até esse momento alcançavam 9,4 bilhões, repercutindo em uma ampliação da capacidade instalada de produção de automóveis da ordem de 629,7 mil unidades, com previsão de geração de 15,5 mil novos empregos diretos [11].

A habilitação ao Inovar-Auto está condicionada à realização, pela empresa, de pelo menos três dos seguintes requisitos no Brasil: atividades fabris e de infraestrutura de engenharia, diretamente ou por terceiros; investimentos em pesquisa, desenvolvimento e inovação, diretamente ou por terceiros; dispêndio em engenharia, tecnologia industrial básica e de capacitação de fornecedores, diretamente ou por terceiros; e adesão da empresa a programa de etiquetagem veicular de âmbito nacional do INMETRO. Podem habilitar-se ao programa 
empresas produtoras, empresas que apenas comercializam ou aquelas que têm projetos de investimentos para novas plantas produtivas no país. No que tange às metas para dispêndios em P\&D (Pesquisa e Desenvolvimento) e dispêndios em engenharia, Tecnologia Industrial Básica (TIB) e capacitação de fornecedores, o Programa já define percentuais mínimos a serem investidos pelas empresas habilitadas nas rubricas (eletivos) [11].

Os principais benefícios da adesão ao Programa Inovar Auto são tributários, através de crédito presumido de trinta pontos percentuais de IPI (Imposto sobre Produtos Industrializados) para as empresas que se habilitarem ao regime (a partir da data de habilitação). Apesar de a adesão ao Inovar-Auto ser facultativa, a criação do programa se deu pouco depois de um aumento de justamente 30 pontos percentuais no IPI de automóveis. Ou seja, a adesão ao Programa gera um diferencial competitivo relevante para as empresas. A partir de 2017, há a possibilidade de abatimento adicional de um ou dois pontos percentuais de IPI, dependendo do consumo energético dos veículos fabricados pela empresa [12].

\subsection{Habilitação ao Programa}

De acordo com a redação do Anexo II do Decreto n 7.819 de 2012, para as empresas se habilitarem ao Programa Inovar-Auto no caso dos veículos leves, a empresa deverá comprometer-se a cumprir, até o dia $1^{\circ}$ outubro de 2017, a exigência de consumo energético máximo (CE1), em MJ/km, calculado conforme a seguinte expressão [13]:

Equação 3: Meta mínima para habilitação ao Inovar-Auto

$C E 1=1,155+0,000593 \cdot($ Mempresa habilitada $)$

Onde $\mathrm{M}$ empresa habilitada é a massa média, em ordem de marcha, em $\mathrm{kg}$, de todos os veículos leves comercializados no Brasil pela empresa habilitada, ponderada pelas vendas ocorridas nos doze meses anteriores ao mês no qual será feito o cálculo [13]. Vale observar que massa em ordem de marcha é definida como sendo a massa do veículo com carroceria (incluídos líquidos, ferramentas e estepe, se instalados, o motorista e um membro da tripulação se o veículo dispõe de assento para tal). Sendo assim, além da massa do carro, seria razoável, de forma aproximada, somar 200 quilos (duas pessoas de 70 quilos, 50 quilos de combustível, 10 quilos das ferramentas e do estepe, aproximadamente) à massa do veículo para calcular a sua massa em ordem de marcha.

O cálculo do consumo energético atingido por cada empresa habilitada será baseado no ciclo de condução combinado descrito na norma NBR 7024, de 2010, e nas instruções normativas complementares do Instituto Brasileiro do Meio Ambiente e dos Recursos Naturais Renováveis (IBAMA) para veículos híbridos e elétricos, e realizado considerando-se o consumo energético de todos os seus modelos de veículos leves ponderados pelas respectivas vendas ocorridas no Brasil [13].

A meta do Inovar-Auto consiste, portanto, em uma média ponderada pelas vendas, e não um nível mínimo universal. Trata-se de uma forma de regulação baseada em atributo (especificamente, a massa em ordem de marcha) com uma curva contínua de metas, dada pela Equação 3.

\section{OBJETIVOS}


As metas do Programa Inovar-Auto, como visto nos itens anteriores, são valores intrínsecos a cada montadora e, portanto, que dependem de seu portfólio de modelos e versões de veículos disponíveis, associado à preferência do consumidor traduzida na forma de licenciamentos. Sendo assim, tais metas não são conhecidas de antemão e precisam ser calculadas tendo como base um ano especifico. Por outro lado, o rendimento médio $(\mathrm{km} / \mathrm{l})$ de todos os modelos/versões disponíveis por montadora também não é um dado conhecido, embora o PBE veicular, descrito no intem 2, venha contribuindo para a mensuração padronizada e publicação do rendimento $(\mathrm{km} / \mathrm{l})$ de uma proporção crescente do total de veículos ofertados no pais.

Logo, o primeiro objetivo deste trabalho consiste em calcular, tanto as metas de habilitação por montadora, como a posição atual das montadoras, ambas em MJ/km, de forma a mensurar o esforço de cada empresa em termos de ganho de eficiência energética para se alcançar os benefícios tributários descritos previamente. De forma complementar, o segundo objetivo está relacionado à mensuração dos resultados do Programa em termos de redução de emissões de Gases do Efeito Estufa (GEE), a partir do menor consumo de combustíveis fósseis ao longo da vida útil dos veículos, considerando-se que as metas de eficiência energética foram alcançadas por todas as montadoras no período de vigência da Lei.

\section{METODOLOGIA}

A metodologia utilizada tem como base o rendimento médio dos veículos vendidos por modelo e por empresa de acordo com o Programa de Etiquetagem Veicular do INMETRO, dados de licenciamentos de veículos da FENABRAVE, e parâmetros de emissão veicular da CETESB. Além dos resultados estatísticos, o trabalho inclui análise de possíveis impactos do Inovar-Auto sobre o perfil de vendas de veículos leves no Brasil e suas repercussões nas emissões de GEE.

\subsection{Cálculo do consumo energético ponderado pelos licenciamentos}

Conforme visto na Seção 3.1, a meta mínima de habilitação ao Inovar-Auto é definida para cada empresa em função de dois atributos: o rendimento energético (dado em $\mathrm{MJ} / \mathrm{km}$ ) e a massa em ordem de marcha dos veículos (em $\mathrm{kg}$ ). Ambos esses atributos devem ser calculados, por cada montadora, em função de uma média ponderada do atributo, seja ele o peso ou o rendimento do veículo. Dessa forma, a Equação 4 foi utilizada para calcular o consumo energético ponderado pelos licenciamentos. Cabe ressaltar que o ano de 2013 foi utilizado como base para os cálculos.

Equação 4: Cálculo do consumo energético ponderado pelos licenciamentos

Rendimento $o_{\text {montador } a_{j}}=\sum \frac{\text { vendas }_{\text {modelo }} \cdot{ }^{i} \text { rendimento }{ }_{\text {modelo }} o_{i}}{\text { vendas }}$

Onde:

Rendiment $_{\text {montador } a_{j}}$ é o rendimento médio da montadora $j$, apurado para fins de habilitação ao Inovar-Auto.

vendas $_{\text {modelo }}$ são as vendas do modelo de veículo $i$, comercializado pela montadora $j$. 
rendimento modelo $_{i}$ é o rendimento, em MJ/km do modelo $i$, comercializado pela montadora $j$.

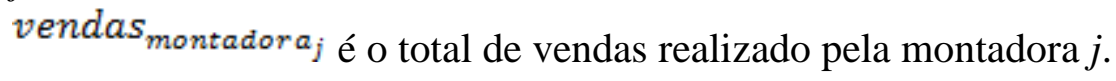

As vendas por modelo tiveram como referência a Federação Nacional de Distribuição de Veículos Automotores (FENABRAVE), a qual indica os 50 modelos mais vendidos de automóveis leves e comerciais leves - os quais representaram mais de $90 \%$ do total de veículos vendidos nessas categorias no ano de 2013 [14]. Com essa informação, é possível calcular também as vendas totais por montadora.

Assim, para que se possa aplicar a Equação 4, foi necessário obter o rendimento, em $\mathrm{MJ} / \mathrm{km}$, de cada um dos 50 modelos de automóveis e comerciais leves mais vendidos no ano de 2013. A referência principal para o rendimento foi o PBE, o qual informa o rendimento dos veículos participantes. Contudo, uma vez que a desagregação por modelo dada pelo PBE é distinta daquela utilizada pela FENABRAVE, no caso de haver mais de um modelo no PBE correspondente a um modelo da FENABRAVE - por exemplo, no caso do modelo Uno da empresa Fiat, enquanto a FENABRAVE informa as vendas de "Uno", no PBE 2013 há 10 modelos de veículos cujo nome é Uno -, adotou-se o rendimento médio como sendo a média entre os extremos informados pelo PBE.

Para os veículos não registrados no PBE 2013, adotou-se as mais diversas referências, sendo a principal a Revista Quatro Rodas. Contudo, uma vez que, à exceção do PBE, nenhuma das referências informa o rendimento veicular em MJ/km (e sim em $\mathrm{km} / \mathrm{l})$, é necessário realizar uma conversão entre as unidades. Segundo a Portaria n. ${ }^{\circ}$ 377, de 29 de setembro de 2011, do INMETRO, quando o rendimento dos veículos é apurado em laboratório, deve ser utilizado um deflator para convertê-lo a condições mais próximas daquelas que são encontradas em uma situação real. Como o rendimento de fontes como a Revista Quatro Rodas é apurada em condições reais, foi necessário realizar o cálculo inverso para averiguar o consumo em condições de teste, conforme é divulgado pelo PBE e será averiguado pelo Inovar-Auto. Usou-se, portanto as Equações 5 e 6, dadas pelo INMETRO [15], para calcular o rendimento, em km/l, do veículos sem utilizar o deflator determinado pela Portaria $\mathrm{n}^{\circ} 377 / 2011$.

Equação 5: Cálculo do rendimento em condições de ensaio para o ciclo urbano

$$
C r_{(k m / l)}=\frac{1}{0,0076712+1,18053 / C t_{(\mathrm{km} / \mathrm{l})}}
$$

Fonte: INMETRO [15]

Equação 6: Cálculo do rendimento em condições de ensaio para o ciclo estrada

$$
C r_{(k m / l)}=\frac{1}{0,0032389+1,3466 / C t_{(k m / l)}}
$$

Fonte: INMETRO [15]

Onde: 
$C r_{(k m / l)}$ é o rendimento real do veículo - aquele divulgado pelo PBE veicular (corrigido com deflator, para refletir o uso cotidiano)

$C t_{(k m / l)}$ é o rendimento verificado em ensaios (sem deflator).

Em seguida, converteu-se o rendimento em $\mathrm{km} / 1$ para $\mathrm{MJ} / \mathrm{km}$ utilizando-se o poder calorífico, densidade e densidade energética dados pelo INMETRO [15], listados na Tabela 1, e, por fim, considerou-se que 55\% do período o veículo seria dirigido na cidade e $45 \%$ na estrada [15].

Tabela 1: Características dos combustíveis para fins de cálculo do rendimento em $\mathrm{MJ} / \mathrm{km}$

\begin{tabular}{|l|l|l|l|l|}
\hline & & E00 & E22 & E100 (AEHC) \\
\hline Poder calorifico & $\mathrm{MJ} / \mathrm{kg}$ & 43,06 & 38,92 & 24,80 \\
\hline Densidade & $\mathrm{kg} / \mathrm{l}$ & 0,735 & 0,745 & 0,810 \\
\hline $\begin{array}{l}\text { Densidade } \\
\text { energética }\end{array}$ & $\mathrm{MJ} / \mathrm{l}$ & 31,65 & 28,99 & 20,09 \\
\hline
\end{tabular}

Fonte: INMETRO [15]

Com todas essas informações, foi possível aplicar a Equação 4 de forma desagregada por montadora, calculando seu rendimento energético médio, o que permite avaliar a situação e o quanto cada montadora precisa melhorar para alcançar sua meta - tema da Seção 5.2.

\subsection{Cálculo das metas de eficiência por montadora}

Seguindo metodologia análoga à utilizada para calcular o rendimento médio, a massa média ponderada pelas vendas de cada montadora é o atributo necessário para que se calcule a meta de cada empresa. A fórmula de cálculo utilizada para calcular a massa média ponderada pelas vendas de cada montadora está disposta na Equação 7:

Equação 7: Cálculo da massa média ponderada pelas vendas por montadora

Massa média $a_{\text {montador } a_{j}}=\sum \frac{\text { vendas }_{\text {modelo }} \cdot{ }^{\text {massa }} a_{\text {modelo }}{ }_{i \mathrm{i}}}{\text { vendas }_{\text {montador } a_{j}}}$

Reunindo os cálculos da Seção 5.1 e 5.2, é possível avaliar a situação atual de cada montadora, bem como sua meta. A Figura 1 exibe a posição de cada montadora avaliada como um ponto azul e a meta de habilitação ao Inovar-Auto como uma linha vermelha. Aquelas montadoras que se situam acima da linha vermelha não haviam alcançado a meta de habilitação do ano 2017 (no ano em que os dados foram avaliados - 2013), enquanto aquelas que se situam abaixo da linha vermelha já haviam alcançado a meta. 
Figura 1: Meta e desempenho atual das montadoras avaliadas

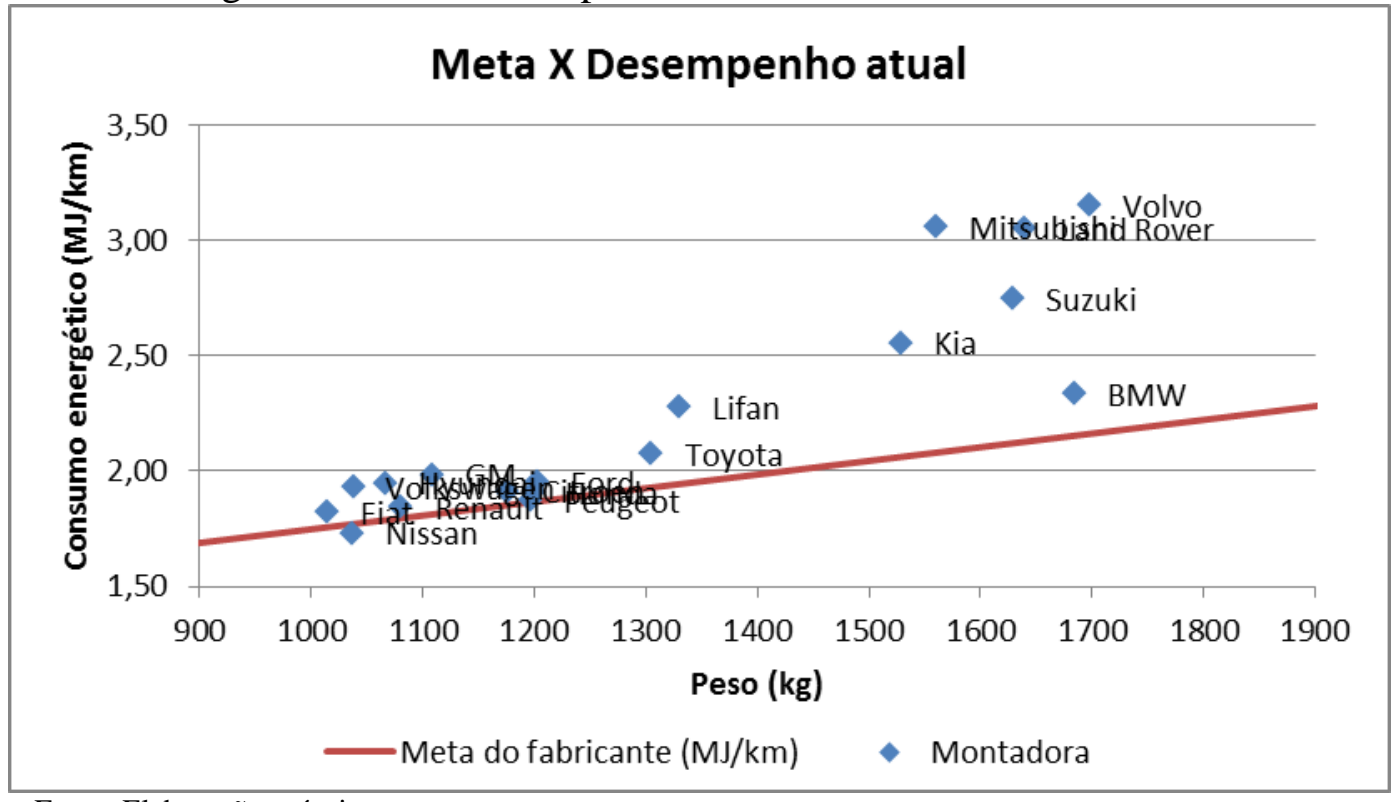

Fonte: Elaboração própria

Pode-se desenhar outras conclusões interessantes a partir da Figura 1. Percebe-se que, em geral, a maior parte das empresas que ocupam segmentos de mercado de veículos mais pesados (acima de $1.500 \mathrm{~kg}$ ) estavam mais distantes da meta que seus pares no segmento de veículos mais leves. É notável também que grande parte dos fabricantes possui uma massa média ponderada pelas vendas entre $1.000 \mathrm{~kg}$ e $1.250 \mathrm{~kg}$ (dez de um total de vinte empresas avaliadas - cabe destacar que foram avaliadas todas as empresas que possuíam pelo menos um veículo dentre os 50 automóveis ou comerciais leves mais vendidos no ano de 2013), o que reflete as características históricas do mercado automobilístico brasileiro, em geral voltado para carros menores e de baixa cilindrada. A Figura 2 ilustra em maior detalhe esse segmento de peso.

Figura 2: Detalhe da meta e desempenho atual das montadoras com massa média ponderada entre 1.000 e $1.250 \mathrm{~kg}$

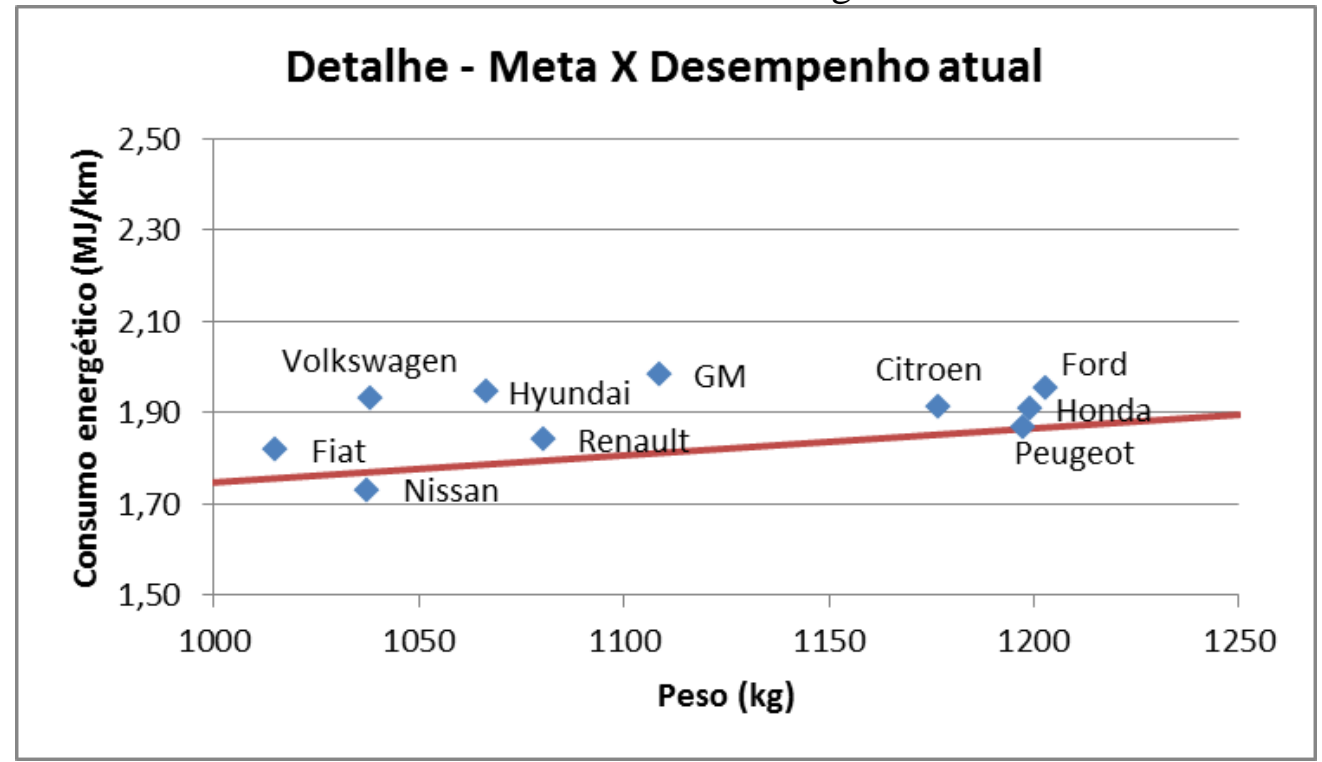

Fonte: Elaboração própria 
Apenas uma, dentre as vinte montadoras avaliadas, cumpriu a meta de eficiência estipulada pelo Inovar-Auto como o mínimo necessário à habilitação ao Programa, meta essa que deve ser alcançada até o ano de 2017. Cabe ressaltar, porém, que devido ao fato de a meta e a situação atual de cada montadora ser determinada em função de uma média ponderada pelas vendas, a situação das montadoras pode se alterar significativamente de um ano para outro mesmo sem alterações na eficiência de seus veículos. Isso pode ocorrer caso as vendas migrem para veículos mais leves/pesados ou eficientes/ineficientes, alterando o resultado da média ponderada.

\subsection{Cálculo das emissões de GEE}

Para calcular o impacto dos ganhos de eficiência energética nas emissões de GEE no período entre o ano base, 2013 e o horizonte de vigência do Inovar Auto, 2017, considerou-se dois cenários:

- Cenário Base: considera que o rendimento médio $(\mathrm{km} / \mathrm{l})$ dos veículos licenciados por tecnologia (gasolina, flex fuel, diesel, híbrido gasolina) é mantido constante ao longo da projeção.

- Cenário Habilitação: considera ganhos constantes de rendimento médio $(\mathrm{km} / \mathrm{l})$ por tecnologia de forma a alcançar ao final do período de projeção as metas de Habilitação ao Programa Inovar Auto calculadas no item 5.2.

O cálculo das emissões em ambos os cenários é feito com base em modelo contábil bottom up de consumo de combustíveis, cujas principais variáveis são: unidades licenciadas de veículos, curva de sucateamento, eficiência média de cada tecnologia, a curva de quilometragem média por idade do veículo, participação do consumo de gasolina em veículos de tecnologia flex fuel e participação do etanol anidro na gasolina $C$.

De acordo com dados da ANFAVEA, em 2013, foram licenciadas cerca de 3,6 milhões de veículos leves, dentre os quais a participação dos comerciais leves foi de $23 \%$ [2]. Tanto a quantidade de veículos licenciados, quanto à distribuição entre automóveis e comerciais leves no total dos licenciamentos foram mantidas constantes ao longo do período de projeção. Já a distribuição por tecnologia nos licenciamentos foi estimada a partir do ranking de automóveis e comerciais leves mais vendidos por modelo publicado pela FENABRAVE [14]. Adotou-se ainda a hipótese de que todos os veículos a diesel são alocados no segmento de comerciais leves e todos os modelos híbridos a gasolina e elétricos são alocados no segmento de automóveis. Nota-se que os veículos elétricos não aparecem no ranking de veículos mais vendidos da FENABRAVE 2013. A participação das tecnologias no licenciamento de veículos foi mantida fixa ao longo do exercício para ambos os cenários.

A equação da curva de sucateamento, que considera a probabilidade de um veículo de determinada idade estar sucateado em determinado ano, tem como fonte o $1^{\circ}$ Inventário Nacional de Emissões Atmosféricas por Veículos Automotores Rodoviários, publicado pelo Ministério do Meio Ambiente (2011) [16]. A equação que considera a distância (km) viajada por veículo considerando-se a idade do veículo, também tem como base esta mesma fonte.

A participação da gasolina no abastecimento dos veículos flex fuel depende tanto da relação de seu preço com o preço do etanol nos postos de revenda, quanto de outros fatores comportamentais do consumidor. Sendo assim, esta participação foi estimada tendo como 
base dados de preço relativo de etanol e gasolina C, em 2013, segundo dados da Agência Nacional de Petróleo, Gás Natural e Biocombustíveis (ANP) [19] e no arcabouço teórico apresentado no trabalho de Avaliação do Comportamento dos Usuários de Veículos Flex Fuel no Consumo de Combustíveis no Brasil, publicado pela EPE [18]. Como resultado, considerou-se que $76 \%$ da distância percorrida com veículos flex fuel, em 2013, foi percorrido utilizando-se gasolina $\mathrm{C}$.

As principais hipóteses adotadas no modelo bottom up de consumo de combustíveis no Cenário Base e no Cenário de Habilitação podem ser observadas na Tabela 2.

Tabela 2: Hipóteses adotadas no modelo de consumo de combustíveis por cenário

\begin{tabular}{|c|c|c|c|}
\hline Hipóteses & Cenário Base & Cenário Habilitação & Fonte de Dados \\
\hline $\begin{array}{l}\text { Evolução das unidades } \\
\text { licenciadas }\end{array}$ & $\begin{array}{l}\text { constante em relação } \\
\text { a } 2013\end{array}$ & $\begin{array}{l}\text { constante em relação } \\
\text { a } 2013\end{array}$ & ANFAVEA (2014) [2]. \\
\hline $\begin{array}{l}\text { Evolução da distribuição dos } \\
\text { licenciamentos entre } \\
\text { automóveis e comerciais } \\
\text { leves }\end{array}$ & $\begin{array}{l}\text { constante em relação } \\
\text { a } 2013\end{array}$ & $\begin{array}{l}\text { constante em relação } \\
\text { a } 2013\end{array}$ & ANFAVEA (2014) [2]. \\
\hline $\begin{array}{l}\text { Evolução da participação das } \\
\text { tecnologias nos } \\
\text { licenciamentos }\end{array}$ & $\begin{array}{l}\text { constante em relação } \\
\text { a } 2013\end{array}$ & $\begin{array}{l}\text { constante em relação } \\
\text { a } 2013\end{array}$ & $\begin{array}{l}\text { própria com base em } \\
\text { FENABRAVE (2013) } \\
\text { [14] e ANFAVEA } \\
(2014)[2]\end{array}$ \\
\hline Sucateamento & $\begin{array}{l}\text { metodologia MMA } \\
(2011)\end{array}$ & $\begin{array}{l}\text { metodologia MMA } \\
(2011)\end{array}$ & MMA (2011) [16] \\
\hline $\begin{array}{l}\text { Distância anual média por } \\
\text { idade do veículo }\end{array}$ & $\begin{array}{l}\text { metodologia MMA } \\
(2011)\end{array}$ & $\begin{array}{l}\text { metodologia MMA } \\
(2011)\end{array}$ & MMA (2011) [16] \\
\hline Rendimentos & $\begin{array}{l}\text { constante em relação } \\
\text { a } 2013\end{array}$ & $\begin{array}{l}\text { Crescimento constate } \\
\text { até alcançar a Meta } \\
\text { de Habilitação do } \\
\text { INOVAR AUTO em } \\
2017 \\
\end{array}$ & $\begin{array}{l}\text { própria com base em } \\
\text { INMETRO (2013) [17] }\end{array}$ \\
\hline \begin{tabular}{|l|} 
Participação do consumo de \\
gasolina em veículos flex fuel
\end{tabular} & $\begin{array}{l}\text { constante em relação } \\
\text { a } 2013 \text {. Considerou- } \\
\text { se } 76 \%\end{array}$ & $\begin{array}{l}\text { constante em relação } \\
\text { a } 2013 \text {. Considerou- } \\
\text { se } 76 \%\end{array}$ & $\begin{array}{l}\text { própria com base em } \\
\text { EPE (2013) [18] e } \\
\text { ANP (2014) [19] }\end{array}$ \\
\hline $\begin{array}{l}\text { Participação de etanol anidro } \\
\text { na gasolina C }\end{array}$ & $\begin{array}{l}\text { constante em relação } \\
\text { a 2013. Considerou- } \\
\text { se 23,5\%. }\end{array}$ & $\begin{array}{l}\text { constante em relação } \\
\text { a 2013. Considerou- } \\
\text { se 23,5\%. }\end{array}$ & $\begin{array}{l}\text { própria com base em } \\
\text { legislação do setor. }\end{array}$ \\
\hline
\end{tabular}

Nota 2: A participação de etanol anidro na Gasolina $\mathrm{C}$ foi estimado com base na legislação do setor.

Fonte: Própria.

Os rendimentos médios $(\mathrm{km} / \mathrm{l})$ dos automóveis e comerciais leves por tecnologia, em 2013, foram calculados segundo a metodologia apresentada no item 5.2. Ressalta-se que o modelo bottom up utilizado não é desagregado entre cidade e estrada. Sendo assim, para cada tecnologia adotou-se a distribuição utilizada pelo INMETRO em que 55\% dos rendimentos são pertinentes ao ambiente cidade e $45 \%$ dos rendimentos referem-se ao ambiente estrada.

Os rendimentos médios $(\mathrm{km} / \mathrm{l})$ dos automóveis e comerciais leves, em 2017, foram calculados com base nas metas de consumo energético máximo $(\mathrm{MJ} / \mathrm{km})$ a serem alcançadas por montadora para se habilitarem ao Programa, conforme metodologia descrita no item 5.2. 
Ressalta-se que para a tecnologia de automóvel híbrido a gasolina utilizou-se o rendimento da média aritmética dos rendimentos dos modelos disponíveis no PBE 2013 e, este valor foi mantido constante até o final do período de exercício.

Com base nestas hipóteses, no Cenário Habilitação, o rendimento dos automóveis com tecnologia flex fuel no caso do uso do etanol deverá apresentar ganhos de eficiência de 1,4\% ao ano, enquanto, no uso de gasolina este aumento deverá ser de 1,3\% ao ano. No caso dos veículos comerciais leves com tecnologia flex fuel, o aumento da eficiência energética deverá ser de $2,4 \%$ ao ano, para o uso de gasolina e $1,1 \%$ ao ano no uso de etanol. Por fim, os veículos com tecnologia dedicada a gasolina deverão ter ganhos de eficiência de 1,3\% ao ano no caso dos automóveis e $2,4 \%$ ao ano no caso dos comerciais leves neste mesmo período. Os resultados da evolução dos rendimentos de automóveis e comerciais leves por tecnologia podem ser observados na Tabela 3 .

Tabela 3: Rendimento médio de automóveis e comerciais leves por tecnologia em 2013 e 2017 (km/l)

\begin{tabular}{|r|r|r|r|r|r|r|r|}
\hline \multirow{2}{*}{ Ano } & \multicolumn{2}{|c|}{$\begin{array}{c}\text { Gasolina dedicado } \\
(\mathbf{k m} / \mathbf{l})\end{array}$} & \multicolumn{2}{|c|}{$\begin{array}{c}\text { Flex (gasolina) } \\
(\mathbf{k m} / \mathbf{l})\end{array}$} & \multicolumn{2}{|c|}{ Flex (etanol) (km/l) } & \multicolumn{2}{c|}{$\begin{array}{c}\text { Híbrido } \\
\text { (gasolina) } \\
(\mathbf{k m} / \mathbf{l})\end{array}$} \\
\hline & automóvel & com.leves & automóvel & com.leves & automóvel & com.leves & automóvel \\
\hline 2013 & 9,8 & 8,5 & 12,2 & 9,5 & 8,4 & 6,2 & 16,8 \\
\hline 2017 & 10,3 & 9,3 & 12,9 & 10,5 & 8,9 & 6,4 & 16,8 \\
\hline
\end{tabular}

Fonte: própria

A partir da comparação dos resultados do modelo contábil bottom up de consumo de combustíveis (gasolina e etanol) resultante do Cenário Base e do Cenário Habilitação, obtevese o potencial de redução no uso de gasolina e etanol ao longo do período de 2014 a 2017. No caso da gasolina A, o consumo evitado chega a 1,2 bilhões de litros, enquanto no caso do etanol anidro e etanol hidratado, o consumo evitado alcança respectivamente 0,4 e 0,5 bilhões de litros.

Finalmente, com base nos volumes evitados de consumo de combustíveis, como consequência dos ganhos de eficiência energética estimulados pelo INOVAR AUTO, pode-se calcular o potencial de redução das emissões de $\mathrm{CO}_{2}$. Com esta finalidade foram utilizados os fatores de emissão de $\mathrm{CO}_{2}$ divulgados pelo IPCC (2006) [20]. O fator de emissão de $\mathrm{CO}_{2}$ para combustão móvel de gasolina automotiva é de $69.300 \mathrm{~kg} \mathrm{CO}_{2} / \mathrm{TJ}$. Ressalta-se que as emissões de $\mathrm{CO}_{2}$ biogênico foram desconsideradas e, assim, não foram contabilizadas as emissões dos combustíveis etanol hidratado, etanol anidro.

A redução acumulada das emissões de $\mathrm{CO}_{2}$ provenientes do consumo de gasolina $\mathrm{A}$ em veículos leves considerando ganhos de eficiência relacionados à meta de habilitação do Programa Inovar auto, entre 2014 e 2017, foi de 2,7 milhões de toneladas.

\section{CONCLUSÃO}

As políticas de eficiência energética constituem um instrumento privilegiado de mitigação de emissões de gases do efeito estufa (GEE) ao proporcionar múltiplos benefícios, como o aumento da segurança energética, estímulo à inovação e redução de custos com a aquisição de 
combustíveis. O Brasil tem demostrado esforço em contribuir com o objetivo global de estabilizar a concentração de GEE na atmosfera, embora não esteja obrigado a atender metas quantitativas no âmbito do Protocolo de Quioto, por ser um país em desenvolvimento. Neste contexto, o país tem avançado na implementação de marcos regulatórios e políticas com intuito de promover a eficiência energética em diversos setores da economia.

No setor de transportes, o Programa Brasileiro de Etiquetagem Veicular (PBEV), coordenado pelo INMETRO é um passo fundamental no que tange a promoção da eficiência energética de veículos leves. Ao proporcionar o conhecimento do rendimento $(\mathrm{km} / \mathrm{l} \mathrm{ou} \mathrm{km} / \mathrm{kwh})$ de parcela crescente dos veículos leves disponíveis para licenciamento no Brasil de forma padronizada através de medições em laboratórios, o PBEV torna possível, por exemplo, estimar o rendimento médio por tecnologia (flex fuel, gasolina, híbrido), categoria (compacto, médio, grande, etc.) e ambiente (cidade ou estrada) dos veículos licenciados a cada ano, de forma cada vez mais precisa.

Sendo assim, além dos benefícios diretos ao consumidor, por proporcionar uma informação que pode contribuir para sua escolha no momento de aquisição, o PBEV possibilita ao planejador compreender de forma casa vez mais detalhada e completa, o estágio atual em termos de eficiência energética veicular em que o Brasil se encontra, as características gerais dos veículos oferecidos pelas montadoras, etc. A partir desses dados primários, é possível então, elaborar de forma mais eficaz novas politicas de eficiência energética, como no caso do Programa Inovar Auto, instituído pela Lei $\mathrm{n}^{\circ}$ 12.715, de 17 de setembro de 2012, com vigência até dezembro de 2017.

As empresas que se habilitarem ao Programa comprometem-se a cumprir, até o dia $1^{\circ}$ de outubro de 2017, a exigência de consumo energético máximo, em MJ/km, que é calculado em função da massa média em ordem de marcha, em $\mathrm{kg}$, da empresa habilitada ponderada pelas vendas ocorridas nos doze meses anteriores ao mês no qual será feito o cálculo. Logo, as metas do Programa são valores intrínsecos a cada montadora e, portanto, que dependem de seu portfolio de modelos e versões de veículos disponíveis, associado à preferencia do consumidor traduzida na forma de licenciamentos. Logo, tais metas não são conhecidas de antemão e precisam ser calculadas a partir de um ano base, que no caso deste trabalho foi 2013.

Com base na metodologia desenvolvida neste trabalho, observa-se que, em 2013, as montadoras apresentaram massa média ponderada pelas vendas entre $1.015 \mathrm{~kg}$, no caso da Fiat e $2.191 \mathrm{~kg}$, no caso da Jeep. Além disso, 50\% das montadoras tinham massa entre 1.000 $\mathrm{kg}$ e $1.250 \mathrm{~kg}$, enquanto apenas 30\% tinham massa acima de $1600 \mathrm{~kg}$. Em relação às metas de habilitação do Inovar Auto, em 2013, apenas a Nissan apresentou consumo energético (1,73 $\mathrm{MJ} / \mathrm{km})$ abaixo da meta $(1,77 \mathrm{MJ} / \mathrm{km})$ para 2017. Analisando-se a relação entre a posição atual de cada fabricante e sua meta em termos de consumo energético (MJ/km), obtém-se que 7 empresas estão em até 5\% acima da meta, 8 empresas situam-se entre $5 \%$ e $25 \%$ acima da meta e, as restantes 5 empresas, estão entre $25 \%$ e $71 \%$ acima da meta. De forma geral, a maior parte das empresas que ocupam segmentos de mercado de veículos mais pesados (acima de $1500 \mathrm{~kg}$ ) estava mais distante da meta que seus pares no segmento de veículos mais leves.

Do ponto de vista da análise dos rendimentos $(\mathrm{km} / \mathrm{l})$ dos veículos por tecnologia, observou-se que, os automóveis e os comerciais leves que utilizam gasolina precisarão ter aumento de, em 
média, $1,3 \%$ ao ano e 2,4\% ao ano, respectivamente para atingir as metas de consumo energético máximo em 2017, a partir do ano base. No caso do uso de etanol, os ganhos de eficiência em automóveis e comerciais leves deverão ser de 1,4\% e 1,1\% ao ano, respectivamente, neste mesmo período. É importante observar que tais taxas de crescimento, a princípio, estão acima dos ganhos de eficiência média anual de veículos novos, intrínseco à evolução da indústria automotiva. No Plano Decenal de Energia (PDE 2023), elaborada pela Empresa de Pesquisa Energética (EPE), por exemplo, admite-se ganhos de 1,0\% a.a. na eficiência média dos veículos novos que entram em circulação no país.

Para se obter o segundo objetivo do trabalho, calcular o impacto dos ganhos de eficiência energética no consumo de combustíveis (gasolina e etanol) e nas emissões de Gases do Efeito Estufa (GEE), foram elaborados dois cenários: $i$ ) Cenário Base, em que os rendimento médio $(\mathrm{km} / \mathrm{l})$ dos veículos licenciados por tecnologia é mantido constante ao longo da projeção e, ii) Cenário Habilitação que considera ganhos constantes de rendimento médio $(\mathrm{km} / \mathrm{l})$ por tecnologia de forma a alcançar ao final do período de projeção as metas de Habilitação. A partir da comparação dos resultados do modelo contábil bottom up de consumo de combustíveis, obteve-se que, ao longo do período de 2014 a 2017, o consumo evitado de gasolina A, álcool anidro e álcool hidratado chega a 1,2, 0,4 e 0,5 bilhões de litros respectivamente. Finalmente, com base nos volumes evitados de consumo de combustíveis, a redução acumulada das emissões de $\mathrm{CO}_{2}$ provenientes do consumo de gasolina $\mathrm{A}$ em veículos leves, entre 2014 e 2017, foi de 2,7 milhões de toneladas.

O impacto dos ganhos de eficiência nos novos veículos licenciados entre 2014 a 2017, sobre a redução do consumo de combustíveis e emissões de $\mathrm{CO}_{2}$ pode ser considerado tímido frente ao seu potencial no longo prazo. Caso as montadoras consigam pelo menos manter o patamar de eficiência energética alcançados em 2017, ao longo dos anos seguintes, estes ganhos se somam e avolumam à medida que a frota cresce e se renova. Além disso, a incorporação de novas tecnologias veiculares e a própria transformação da cadeia de produção de autopeças favorece a incorporação de novos ganhos tecnológicos. Por fim, o Programa Inovar Auto é um marco em termos de política de eficiência energética para veículos leves no Brasil e sua implementação representa um amadurecimento em termos regulatório, institucional e de gestão, o que abre caminhos para novas fases do Programa.

\section{REFERÊNCIAS}

[1] Empresa de Pesquisa Energética (EPE). Balanço Energético Nacional 2014. Disponível em http://www.epe.gov.br. Acesso em: maio de 2015.

[2] Associação Nacional dos Fabricantes de Veículos Automotores (ANFAVEA). Anuário da Indústria Automobilística Brasileira 2015. Disponível em http://www.anfavea.com.br. Acesso em: maio de 2015.

[3] Empresa de Pesquisa Energética (EPE). Plano Decenal de Energia 2023. Disponível em http://www.epe.gov.br. Acesso em: abril de 2015.

[4] LUBETSKY, J. F. History of Fuel Economy. Pew Environment Group. 2011. 
[5] EPA. EPA and NHTSA Set Standards to Reduce Greenhouse Gases and Improve Fuel Economy for Model Years 2017-2025 Cars and Light Trucks. Environmental Protection Agency. 2012.

[6] UNEP. The European Union Automotive Fuel Economy Policy. United Nations Environment Programme. [S.1.]. 2013. Disponível em:

http://www.unep.org/transport/gfei/autotool/case_studies/europe/cs_eu_0.asp. Acesso em 21/05/2015.

[7] Instituto Nacional de Metrologia, Normalização e Qualidade Industrial (INMETRO). O Programa Brasileiro de Etiquetagem. Disponível em: http://www2.inmetro.gov.br/pbe/. Acesso em: abril de 2015.

[8] Instituto Nacional de Metrologia, Normalização e Qualidade Industrial (INMETRO). Metodologia para Divulgação de Dados de Consumo Veicular. Disponível em: http://www2.inmetro.gov.br/pbe/. Acesso em: março de 2015.

[9] SCHMITT, W. F. Metodologia de Avaliação de Eficiência Energética em Veículos Leves e seus Impactos em Termos de Uso de Combustíveis. UFRJ/COPPE. Rio de Janeiro, p. 197. 2010. Orientadores: Alexandre Salem Szklo e Roberto Schaeffer.

[10] Ministério de Minas e Energia (MME). Selo CONPET de Eficiência Veicular. Disponível em: http://www.conpet.gov.br/Acesso em: março de 2015.

[11] Agência Brasileira de Desenvolvimento Industrial (ABDI). Plano Brasil Maior Inovar para Competir. Competir para Crescer. ABDI 2011-2014. Brasília DF/Brasil, 2015 .

[12] ZURLI, Bernardo. Impacto Energético de Políticas de Eficiência de Eficiência Veicular no Brasil. Rio de Janeiro. COPPE/UFRJ, janeiro de 2014.

[13] BRASIL. Decreto no 7.819 de 3 de outubro de 2012. Brasília DF/Brasil, 2012.

[14] Federação Nacional da Distribuição de Veículos Automotores (FENABRAVE). Informativo Fenabrave. Resumo Mensal Dezembro de 2013. Disponível em: http://www3.fenabrave.org.br Acesso em: março de 2015.

[15] Instituto Nacional de Metrologia, Qualidade e Tecnologia. Programa Brasileiro de Etiquetagem Veicular (INMETRO). Portaria n. ${ }^{\circ}$ 377, de 29 de setembro de 2011. Ministério do Desenvolvimento, Indústria e Comércio Exterior. Brasília DF/Brasil, 2011.

[16] Ministério do Meio Ambiente (MMA). $1^{\circ}$ Inventário Nacional de Emissões Atmosféricas por Veículos Automotores Rodoviários. Ministério do Meio Ambiente. Brasília DF/Brasil, 2011.

[17] Instituto Nacional de Metrologia, Qualidade e Tecnologia. Programa Brasileiro de Etiquetagem Veicular (INMETRO). Tabelas de Consumo/Eficiência Energética 2013. Veículos Automotores Leves. Categoria Todas. Disponível em:

http://www.inmetro.gov.br/consumidor/tabelas_pbe_veicular.asp Acesso em: abril de 2015. 
[18] Empresa de Pesquisa Energética (EPE). Avaliação do Comportamento dos Usuários de Veículos Flex Fuel no Consumo de Combustíveis no Brasil. Brasília/DF, 21 de fevereiro de 2013.

[19] Agência Nacional de Petróleo, Gás e Biocombustíveis (ANP). Boletim Anual de Preços 2014. Rio de Janeiro. ANP, 2014.

[20] Intergovernmental Panel on Climate Change (IPCC). IPCC Guidelines for National Greenhouse Gas Inventories. National Greenhouse Gas Inventories Programme. 2006. 